\title{
The Introduction of Academic Articles on Civil Engineering and Its Linguostylistic Analysis
}

\author{
Minoo Khamesian \\ Yerevan State University
}

\begin{abstract}
$\mathrm{T}$ he strategy of participants' behavior in the field of science communication is implemented through specific speech acts, which are the optimal choice of means and methods of communication. What matters is not only the choice of style but the choice of genre and compositional form of the text. The properties of written scientific texts are the result of the language use on the basis of certain "communication code", which operates in a scientific corporative community. This code is based on common conventions and rules of communication and is supplemented with standards inside the corporative community. Through this community the process of intercultural communication in science is developing and expanding. Unlike in other areas written communication plays a vital role in science.

Research articles in English favor the prestigious status of being the major channel of sharing scientific knowledge among the members of academic/domain specific discourse community mainly because of the position of English as the international language of science and technology. In the world of an increasing international academic and research collaboration, the ability to read and write research articles in English is crucial for academic success (Kanoksilapatham 2005). Like other genres, research articles possess their own communicative and rhetorical conventions.

To facilitate the long and arduous process of getting accepted as academic discourse community members, especially at its initial stage, this study focuses on the analysis of a civil engineering data set to investigate how research articles are constructed. Civil engineering is known to be an academic discipline dating back to the year of 1711, when John Smeaton, the founder of a Society of Engineers and the builder of the famous Eddystone Lighthouse in Great Britain, claimed to be the first civil engineer $(<\mathrm{http}$ ://whatiscivilengineering.csce.ca/ civil1.htm $>$ ). With this long history, needless to say, any academic institution in the world that offers a degree in engineering tends to offer a degree in civil engineering. An insight into the analysis of civil engineering articles will thus be beneficial to a large number of scholars, practitioners and fellow students in the field.

Hence, the present article will attempt to scrutinize various linguistic patterns of the introductory part of a civil engineering research article successfully published in the International Journal of Civil Engineering, allowing scientists and practitioners in the field to both effectively share and update their scientific knowledge and contribute to the growth of the discourse community.

We should hasten to add that Introduction is evaluated as the representation of the entire content of papers. As a result, readers often make the introduction as the guide to understanding the content of the research paper. Even to some readers, Introduction is a guide to deciding whether they need to continue reading or the content satisfies their needs.
\end{abstract}


The passage adduced below presents the introductory part of a research article in Civil Engineering.

In designing an ordinary moment resisting frame, often the principle of strong-column-weak beam is implemented in order to make sure that plastic hinging occurs in the beams and as such the frame is capable of dissipating significant energy while remaining stable in the inelastic region. The stability in this context is defined as the ability of the frame to maintain its elastic level of resistance throughout the entire inelastic range of response. Using this principle, plastic hinges would develop in the beams adjacent to the joints and usually very close to the column face. The problem is that this closeness may allow cracks caused by plastic hinging to propagate into the joint core region and as such initiate a brittle failure mechanism.

Attempts have been made in the past in order to develop methods of relocating a plastic hinge away from the column face. Most of the methods, however, have been on detailing of reinforcing bars, which can only be utilized in new construction. For example, Abdel-Fattah and Wight [1] showed that the use of intermediate longitudinal beam reinforcement combined with extra top and bottom steel in the beam at a specific length can help in successfully relocating a plastic hinge away from the column face. The relocating was also studied by Jon et al. [2]. Four half-scale RC interior beam-column joints with different reinforcement details in the beam in the region adjacent to the column were tested under cyclic loads in their investigation. Their results showed that the bond deterioration within the joint may be prevented by the relocation of plastic hinge, while shear sliding may occur at the plastic hinge zone due to the increased shear force at the beam end. Jon et. al. [2]) proposed a new arrangement for the beam bars in order to improve the plastic hinging. Paulay and Priestley [3] also proposed that the beam bars may be curtailed so that stresses in the reinforcement would not exceed yield stress at the face of the column, while strain hardening may be developed at the critical section of the plastic hinge. Paulay and Priestly [3] concluded that the critical section must be a sufficient distance away from the column face. They recommended that because the nature of shear transfer across the critical section of a plastic hinge is complicated, care must be taken with detailing of the shear reinforcement. Paulay and Priestley [3] proposed that this necessitates stirrups extending between these two regions, perhaps supplemented by specially bent top beam bars, to carry the entire shear force and also suggested that to ensure that the critical section occurs at a chosen place, extra flexural reinforcement can be provided by bending some of the top and bottom bars at the angle of $45^{\circ}$ or less into the opposite face of the beam. 
Many already existing moment resisting frames do not posses correct joint reinforcement detailing as they have been designed based on older codes. A different method which can upgrade the joints of these frames in an efficient and cost effective way is consequently desirable. This paper presents results of an experimental investigation into the effectiveness of FRP wraps in controlling the location of a plastic hinge in an Ordinary Moment Resisting Frame (OMRF). The proposed method is to stick carbon FRP sheets of specific lengths to the sides of the beams of a reinforced concrete joint (i.e. web-bonded FRP) and extend them over the joint to act as an anchor. The performance of this method has been investigated by the authors and is presented in the following. Other aspects of the investigation can be found in papers [4, 5]. The method can be used just as effectively for the repair of earthquake damaged $R C$ exterior joints.

This introductory part presents how a new method can promote the joints of moment resisting frames in order to avoid the problem of cracking by plastic hinging which proliferates into the joint core region and brings about a brittle failure mechanism.

As has widely been mentioned the method of linguostylistic analysis (Akhmanova 1972) is quite a safe and reliable method to be applied to any linguistic material as it can help the investigator bring out all possible linguistic peculiarities of the given discourse. Understanding the direct, nominative meanings being our very first task in the investigation (entirely based on dictionaries of contemporary English), we start with such words as:

Verbs: implement, maintain, present, extend, investigate;

Nouns: frame, principle, reinforcement, performance;

Adjectives: capable, stable, adjacent, effective.

Our research has revealed the following nominative meanings:

Implement: (1) to give practical effect to and ensure of actual fulfillment by concrete measures, (2) to provide instruments or means of expression for (Webster 2008).

Maintain: (1) to keep in an existing state (as of repair, efficiency, or validity), (2) preserve from failure or decline (maintain machinery) (Webster 2008).

Present: to act the part of; perform (Webster 2008).

Extend: to cause to be of greater area or volume; enlarge (Webster 2008).

Investigate: to carry out a systematic or formal inquiry into (an incident or allegation) so as to establish the truth (Concise Oxford English Dictionary 2004).

Frame: a rigid structure surrounding a picture, door, etc. (Concise Oxford English Dictionary 2004).

Principle: a general scientific theorem or natural law (Concise Oxford English Dictionary 2004). 
Reinforcement: act of strengthening, fortification (Babylon English Dictionary 2009).

Performance: the manner of reacting to stimuli (Webster 2008).

Capable: having attributes (as physical or mental power) required for performance or accomplishment (Webster 2008).

Stable: firmly established (Webster 2008).

Adjacent: having a common endpoint or border (Webster 2008).

Effective: producing a decided, decisive, or desired effect (Webster 2008).

As is usually assumed, the basic function of scientific writing is to elaborate on certain points or assumptions; define and explain different phenomena, pass on and sum up information, arrive at certain conclusions. In other words, the process of scientific work is mainly reflected in general scientific vocabulary, which has been singled out in the following conceptual fields (the examples are taken from the sample adduced above):

1) prospect, outlook (attempt, propose, etc.);

2) acquiring knowledge (investigate, study, etc.);

3) organization and systematization (combine, result, etc.);

4) checking up (relocate, test, etc.);

5) making conclusions (conclude, effective, etc.);

6) passing on knowledge (suggest, can be used, etc.).

(Gasparyan 1998)

From the point of view what has been mentioned above, it can be concluded that words belonging to the general scientific vocabulary deal with processes of acquiring and passing on information, making prospects, arriving at certain results, checking them, making conclusions, and so on. As a result, according to Akhmanova (1978), the lexical "diapason" (range) of words in scientific writings is naturally narrowed down, which means, they totally acquire special meanings. In other words, general scientific words remain general only in the sense that they appear to be simple and familiar and can easily be considered as functioning in all registers of speech. However, when they are used in a scientific text, a certain transposition of their meaning is bound to occur.

The grammatical-morphological study of the vocabulary notes of the passage (frequency analysis) shows that nouns in this passage prevail and it is discernible that the introductory part of the above civil engineering material presents a technical object, namely FRP (the effectiveness of FRP wraps in controlling the location of a plastic hinge in an Ordinary Moment Resisting Frame (OMRF)).

On the level of word groups (Lexical-Phraseological word combinations) the use of noun compounds, such as ordinary moment resisting frame; correct join reinforcement; joint core region; brittle failure mechanism, etc. prevails. This is in line with the style of scientific prose for it is believed that the mentioned constructions are used as a means to represent information in a compact and dense form. Also as Ferguson (2004) illustrates noun compounds can be used as technical terms as well (ordinary moment resisting 
frame). In this sense they can be used in the introduction to indicate the first technical concept. In this connection we may continue by considering the interaction of vocabulary and syntax in greater detail. Although ultimate syntagmatic sequences are larger than words and mostly include the expression of predication, they are generally applicable, highly reproducible complexes which may be regarded as functionally similar to nominative units, e.g.: ... in order to make sure that..., ... in this context is defined as ..., The method can be used just as effectively for the ... to name but a few. We should hasten to add here that the number of attributive word-combinations (significant energy, inelastic region, older code, experimental investigation, etc.) prevails, as well as the so called of-phrases (elastic level of resistance, range of response, the principle of, the effectiveness of) and so on.

Our analysis on the level of words and word-combination reveals that these groups are mainly non-connotative and devoid of any emotional colouring. As has always been assumed by and large, in intellective communication the speaker or writer whose main aim is to pass on information does not mainly rely on the power of words and utterances, i.e. on their connotative values.

With respect to morphological-grammatical analysis the most important oppositions are between the present and the past, active and passive. Similar to other scientific writings the use of verbal phrases in the passive is prevalent, such as is implemented, is defined, have been designed, has been investigated, to name but a few. As is frequently mentioned by scholars passive constructions play a very important role, for they serve to express general statements about things without bothering to introduce doers into the statements. Needless to say the present tense appears almost throughout the whole passage as informative works are not restricted by time. As regards the present perfect tense, it should be noted that it is the form which helps to establish a direct contact with the interlocutors, being so much more situation-bound.

On the level of major syntax, complete (non-elliptical) complex and compound sentences with the secondary clauses of cause, effect and condition which enable the author to express the relations between the parts more precisely (as different from the asyndetic connection typical of colloquial speech) constitute a high percentage. For example: In designing an ordinary moment resisting frame, often the principle of strong-column-weak beam is implemented in order to make sure that plastic hinging occurs in the beams and as such the frame is capable of dissipating significant energy while remaining stable in the inelastic region.; Many already existing moment resisting frames do not posses correct joint reinforcement detailing as they have been designed based on older codes.

The syntactic semi-composite sentences, i.e. absolute constructions (ACs) with two predicative lines, the first being the main clause, the second extending it via incomplete secondary predication are wide usages. The absence of a finite verb in the sentence is considered to be one of the types of secondary predication (Karapetyan 2010). In our analysis we come across such cases as in In designing an ordinary moment resisting frame, often the principle of strong-column-weak beam is implemented in order to make sure that plastic hinging occurs in the beams and as such the frame is capable of dissipating significant energy while remaining stable in the inelastic region.; Using this 
principle, plastic hinges would develop in the beams adjacent to the joints and usually very close to the column face.

As is known, the ever-increasing rhythm of scientific development requires transmission of information in the linguistic frame as compressed as possible, and the absolute constructions (ACs) due to their structural incompleteness, which nonetheless does not distort the meaning they transfer, contribute to the beneficial evolution of the discourse, make the speech compact and neat, and give an opportunity to fit more information into a lesser volume.

Sentence patterns applied are of three types;

1) Postulatory, i.e. a hypothesis must be based on facts already known. Therefore, every piece of scientific prose will begin with postulatory pronouncements which are taken as self-evident and needing no proof. E.g. In designing an ordinary moment resisting frame, often the principle of strong-column-weak beam is implemented in order to make sure that plastic hinging occurs in the beams and as such the frame is capable of dissipating significant energy while remaining stable in the inelastic region.

2) Argumentative, that is, the writer's own ideas are shaped in formulae, arguments, etc., in other words, in sentences giving reasons for further conclusions. E.g. The problem is that this closeness may allow cracks caused by plastic hinging to propagate into the joint core region and as such initiate a brittle failure mechanism.

Formulative, that is to say, the definition sentence-pattern which is the sentence which sums up the facts is generally a kind of clincher sentence which is in line with scientific prose writing in general. E.g. The method can be used just as effectively for the repair of earthquake damaged $R C$ exterior joints.

As it is widely accepted, a hypothesis, a scientific conjecture or a forecast must be based on facts already known, on facts systematized and defined. Therefore; every piece of scientific prose will begin with postulatory pronouncements which are considered as self-evident, needing no proof. A reference to these facts is only preliminary to the exposition of the writer's viewpoints and is therefore summed up in precisely formulated statements accompanied by references to sources.

When speaking about syntax, it is important to elaborate on the functional perspective of paragraphs or the supraphrasal unities which exist as part of a discourse, as elements in a series of intertwined syntactic entities which jointly serve for the expression of wider, overall purports. Consequently, the division of a text into paragraphs, i.e. the paragraph as a semiotic device, and the average length of paragraphs could be an important conclusion to make.

In the introductory part presented above the average length of paragraphs is 13-14 lines, which in actual fact is not in line with what is recommended in scientific writings. But it goes without saying that what really matters in a piece of scientific writing is its careful edition in terms of division into paragraphs (Akhmanove 1978).

The general function of the Introduction section is to introduce the topic, furnishing the rationale for the study being reported. Building on the notion of shared communicative purposes Swales (1990) suggests "rhetorical movement" analysis (move and step analysis) as the basis for explaining a genre. When applied to the introductory section 
adduced above this mechanism of analysis offered by Swales proves to be productive and can be illustrated in the following way: the analysis shows that the first step of move 1 (Claiming centrality) is absent here as there is no evidence of the kind to support step 1. On the other hand, the presence of the second step can be specified by the use of lexicalgrammatical vocabulary with often in: often the principle of ... is implemented in order to make sure that ... which is considered as the statement to elaborate on either knowledge, consensus, practice or description of phenomena. Step 3 (Reviewing items of previous research) is present in the introductory part adduced above by using already in Many already existing moment resisting frames do not possess correct joint reinforcement detailing as they have been designed based on older codes. Here, the writer needs to represent what has been found or claimed and possibly, who has found or claimed it. After describing important features of their research territory (Move 1), academic writers typically try to claim a "niche" for their research. This move can be done by showing that the previous research or solutions are not complete, or that there are aspects of the research field still needing further investigation (indicating a gap). This is often signaled by words expressing contrast or negative evaluation as in A different method which can upgrade the joints of these frames in an efficient and cost effective way is consequently desirable. Finally in Move 3 (Occupying the niche) the writers reveal their solution to help fill the gap that has been presented in Move 2 by describing the aims in terms of what the research sets out to do or accomplish using either human or inanimate agents as the subject as in This paper presents results of an experimental investigation into the effectiveness of FRP wraps in controlling the location of a plastic hinge in an Ordinary Moment Resisting Frame (OMRF). Needless to say, here the writer uses an inanimate agent to perform the step (Announcing present research).

Thus, Generic patterns commonly intertwined in academic discourse across disciplines (Civil Engineering research articles, the core in this study) are so complex that a system of linguistic analysis is required to account for the intricacies in order to be handled by the members of specific discourse communities. Students will benefit from the findings of the present study if they are made aware of not only rhetorical moves, but also of the linguistic patterns associated with them. As this leads to a degree of standardization which suggests that research papers may share a common basic structure, or employ common units within the scientific genre.

\section{Notes:}

1. Move 1 = Establishing a territory. Step $1=$ Claiming centrality. Step $2=$ Making topic generalization (s). Step 3 = Reviewing items of previous research.

Move 2 = Establishing a niche. Step 1 = Indicating a gap.

Move 3 = Occupying the niche. Step 1 = Announcing present research (Swales 1990: 141, Figure 10). 


\section{References:}

1. Akhmanova, O.A.; Idzelis, R.F. (1978) What is the English We Use? M.: MUP.

2. Ferguson, G. (2004) Handout: Lecture on the Grammar in ESP: Noun Compound. UK: University of Sheffield.

3. Gasparyan, S.K. (1998) ESP as an Object of Learner-Oriented Teaching. // Didaktik und Methodik des Fremdsprachen Unterrichts. Heft, IV. Köln.

4. Kanoksilapatham, B. (2005) Rhetorical Structure of Biochemistry Research Articles. // English for Specific Purposes, 24, 3.

5. Karapetyan, R. (2010) On the Syntactic Status of Absolute Constructions. Yerevan: YSU.

6. Swales, J. (1990) Genre Analysis: English in Academic and Research Settings. Cambridge: CUP.

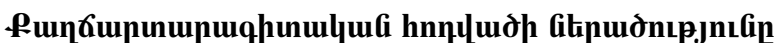

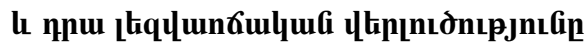

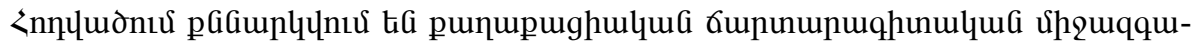

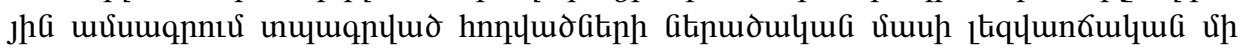

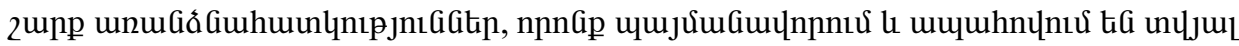

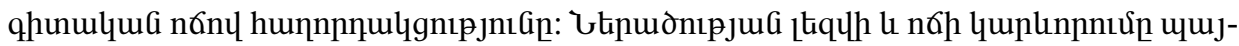

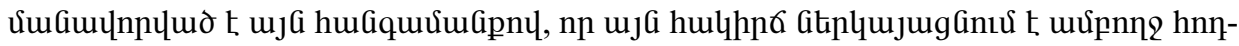

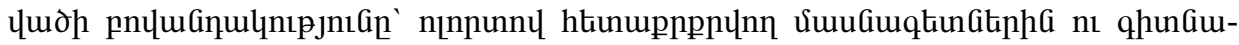

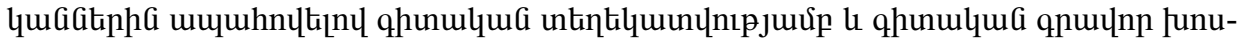

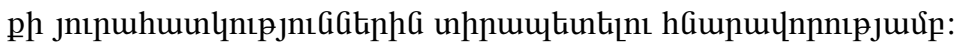

